\section{The Appeal of Biodegradable Packaging to Floral Consumers}

Charles R. Hall ${ }^{1,7}$

Department of Horticultural Sciences, Texas A\&M University, 202 Hort/

Forest Science Building, 2133 TAMU, College Station, TX 77843-2133

Benjamin L. Campbell ${ }^{2}$

Department of Agricultural Economics, Texas A\&M University, College Station, TX 77843

Bridget K. Behe ${ }^{3}$

Department of Horticulture, Michigan State University, East Lansing, MI 48824-1325

\section{Chengyan Yue ${ }^{4}$}

Department of Applied Economics and Department of Horticultural Science, University of Minnesota, St. Paul, MN 55108

Roberto G. Lopez ${ }^{5}$

Department of Horticulture and Landscape Architecture, Purdue University, West Lafayette, IN 47907

\section{Jennifer H. Dennis ${ }^{5,6}$}

Department of Horticulture and Landscape Architecture and the Department of Agricultural Economics, Purdue University, West Lafayette, IN 47907

Additional index words. marketing, market segmentation, environmentally friendly, conjoint analysis, biodegradable

\begin{abstract}
Currently, one of the most widely discussed topics in the green industry, which is promulgated by consumers exhibiting greater degrees of environmental awareness, is the issue of environmental sustainability. This has led to a desire for products that not only solve the needs of consumers, but are also produced and marketed using sustainable production and business practices. Consumers increasingly place a greater emphasis on product packaging and this has carried over to the grower sector in the form of biodegradable pots. Although various forms of these eco-friendly pots have been available for several years, their marketing appeal was limited as a result of their lessthan-satisfying appearance. With the recent availability of more attractive biodegradable plant containers, a renewed interest in their suitability in the green industry and their consumer acceptance has emerged. The objective of this study was to determine the characteristics of biodegradable pots that consumers deem most desirable and to identify distinct consumer segments, thus allowing producers/businesses to more efficiently use their resources to offer specific product attributes to those who value them the most. We conducted a conjoint analysis through Internet surveys with 535 valid observations from Texas, Michigan, Minnesota, and Indiana. Our results show that on average, consumers like rice hull pots the most followed by straw pots. Our analysis identified seven market segments and corresponding consumer profiles: "Rice Hull Likers," "Straw Likers," "Price Conscious," "Environmentally Conscious," "Carbon Sensitive," "Non-discriminating." Idiosyncratic marketing strategies should be implemented by industry firms to market biodegradable containers to the identified consumer segments.
\end{abstract}

The commercial greenhouse and nursery industries often produce crops in plastic containers of varying sizes and shapes depending on the crop and target market (Evans and Hensley, 2004). Plastic containers serve the role of consumer packaging, transportation container, sometimes marketing vehicle as well as propagation and production receptacle and therefore must be strong, compatible with automation, horticultural uses, and able to be formed to essentially any size, shape, and color (Evans and Hensley, 2004; White, 2009). Containers, trays, cell packs, and flats are used for the
In 2003, the United States generated $\approx 11$ million tons of plastic in the municipal solid waste stream as containers and packaging [Environmental Protection Agency (EPA), 2007], which comprised a third of all municipal solid waste (EPA, 2005). Nationwide, only $3.9 \%$ of the 26.7 million tons of plastic generated in the United States was recycled in 2003 according to the EPA (2007). Most of the recycled plastic was from beverage containers, including soda pop and milk. Agricultural plastics are challenging to recycle or reuse as a result of contamination problems or ultraviolet light degradation. Recycling facilities are often unwilling to accept plastics with soil or media residue. If recycling facilities clean and process the plastics, collection and shipment fees increase as a result of the heavier weight and increased transportation expenses (Garthe and Kowal, 1993). Two types of contamination unique to agriculture are ultraviolet light degradation and pesticide residue (Garthe and Kowal, 1993). Ultraviolet light and heat degradation are caused by exposure to extreme sunlight and heat, which lessens the value of the plastics resulting from loss of flexibility and recyclability (Garthe and Kowal, 1993). Typically, these non-reusable or non-recyclable plastic containers are disposed by consumers and landscapers, thus presenting a significant disposal issue for the horticulture industry (Evans and Hensley, 2004).

In recent years, the floriculture industry has seen a rise in biodegradable, compostable, or bioresin containers often called "green" products (Lubick, 2007). These "green" containers have emerged to take advantage of the green marketing and environmental awareness related to high fuel prices (Kale et al., 2007). Containers made of bioresins have the characteristics of plastics without the petroleum base. These containers are derived with renewable raw materials such as starch (e.g., corn, rice hulls, wheat, and so on), cellulose, soy protein, and lactic acid (White, 2009). Therefore, they are often labeled as compostable because they are broken down by naturally occurring microorganisms into carbon dioxide, water, and biomass when composted or discarded (White, 2009).

Biodegradable containers are those that can be planted directly into the soil or composted and will eventually be broken down by microorganisms (Evans and Hensley, 2004; White, 2009). Most biodegradable containers are made of peat, paper, or coir fiber, with peat containers being the most prevalent (Evans and Hensley, 2004). Other examples of biodegradable container materials include spruce fibers; sphagnum peat; wood fiber and lime; grain husks, predominantly rice hulls; $100 \%$ recycled paper; nonwoven, degradable paper; dairy cow manure (GreenBeam Pro, 2008); corn; coconut; and straw (Biogro-pots: Eco Friendly, 2007; Van de Wetering, 2008). Some of the reported benefits of using biodegradable and compostable containers include an elimination of plastic waste, stronger and healthier plants, 
less disturbance of roots during transplanting, and the "feel-good factor" of the grower (Martin, 2008).

Consumers are not all alike. They have different attitudes, preferences, and behavior and differ with regard to their acceptance and purchase of new products (Kotler and Keller, 2006). Groups of consumers create markets. Thus, market segments have characteristics that can be quantified and distinguishable. Consumers think and act differently in response to ideas and products; ornamental plant containers are no different. Consumers impart a different relative importance to products and even features within those products, assigning value and importance through past purchases and future purchase intentions. The presence of environmentally sensitive or "green" consumers has been acknowledged for some time and such consumers are more likely than the general population to take environmentalism into account when purchasing goods. The presence of such consumers has also been assumed to bring profits to companies with a record of environmentally friendly practices (Russo and Fouts, 1997). Most research has found that many consumers are willing to pay a premium price for green products and share attitudes that are favorable to the environment (Engel and Potschke, 1998; Guagnano et al., 1994; Laroche et al., 2001; Schegelmilch et al., 1996; Straugh and Roberts, 1999), yet not all consumer attitudes about the environment are the same (Gladwin et al., 1995; Purser et al., 1995).

Despite the introduction of green products as alternatives to already existing ordinary products, many customers still choose ordinary products with lower "environmental quality" because of price and performance considerations or ignorance and disbelief (Ottman, 1998). Like most innovation activities, green product development is a task characterized by high levels of risk and uncertainty and the introduction of biodegradable containers into the Green industry marketplace is no exception.

Unfortunately, the impact of differing consumer attitudes about the environment on their willingness to pay a premium price for those products has not been explored in

Received for publication 2 Dec. 2009. Accepted for publication 21 Jan. 2010.

We gratefully acknowledge funding from the American Floral Endowment (AFE), the Horticultural Research Institute (HRI), and the FederalState Marketing Improvement Program (FSMIP) that was instrumental in conducting this research effort.

${ }^{1}$ Ellison Chair in International Floriculture.

${ }^{2}$ Assistant Lecturer and Post Doctorate Research Associate.

${ }^{3}$ Professor.

${ }^{4}$ Bachman Endowed Chair in Horticultural Marketing.

${ }^{5}$ Assistant Professor.

${ }^{6}$ Associate Professor.

${ }^{7}$ To whom reprint requests should be addressed; e-mail chall@ag.tamu.edu. the literature. That is, researchers have yet to "unpack" the notion of the green consumer. For example, considering green consumers in the aggregate may mask important distinctions within the group. Unfortunately, there is little work that explores segmentation within the consuming populace on this dimension.

The objective of this study was to determine the characteristics of biodegradable pots that consumers deem most desirable and solicit their preference for this type of sustainable product. Additionally, we wanted to determine the size and develop a profile of the consumer segment(s) that would be more likely to purchase a nursery or greenhouse plant produced and marketed in biodegradable containers made from non-plastic components. We hypothesized that consumers with certain demographic characteristics (age, income, gender) or attitudinal and behavioral (already recycling other materials) have a moderate to high level of interest and will more likely consider purchasing containers made from alternative (non-plastic) materials. This type of segmentation will greatly benefit the Green industry by ensuring that environmentally friendly products marketed to floral consumers in the future truly meet their "sustainability" needs and/or expectations.

\section{Materials and Methods}

Conjoint analysis is a key technique for evaluating consumer preferences for predetermined combinations of product attributes. Results of conjoint analysis studies have commonly allowed for not only the comparison of consumer preferences between products and attributes, but also both market segmentation and simulations. Numerous studies have examined preferences for a wide variety of horticultural issues using conjoint analysis. Hopman et al. (1996) used conjoint analysis to obtain grower preferences for horticultural locations, whereas Lin et al. (1996) evaluated professional buyer preferences for organic produce. More traditional studies have tended to try and better understand consumer preferences of consumer products. Horticultural products included asparagus (Behe, 2006), bell peppers (Frank et al., 2001), Christmas trees (Behe et al., 2005a), satsuma mandarins (Campbell et al., 2004, 2006), and fresh-market tomatoes (Simonne et al., 2006). Research has also focused on horticultural products more notably identified with the green industry such as edible flowers (Kelley et al., 2002), landscapes (Behe et al., 2005b), and geraniums (Behe et al., 1999).

Baker (1998) noted that a consumer's valuation of a product is directly related to the utility or satisfaction associated with each attribute that comprises the product. If we allow a consumer to evaluate enough combinations of attributes, then we can determine the utility (value) associated with each attribute and, thereby, the product as a whole. For instance, if a consumer evaluates two products with only one attribute varied, say price, between them, then we can determine how much value the consumer gives to the attribute in question.

Attributes. Establishing the key product attributes and attribute levels is essential for any conjoint study. For this study, we consulted with industry experts and retailers to identify container attributes and their corresponding levels that were considered to be environmentally important to consumers while directly controlling for other attributes considered to be of lesser importance. Product attributes (and levels) identified were container price (\$2.49, \$2.99, \$3.49), material (plastic, wheat starch, rice hulls, straw), carbon footprint (neutral, saving, intense), and waste composition $(0 \%, 1 \%$ to $49 \%$, greater than $49 \%$ ).

Price has been shown to be a critical factor in most consumers' buying decisions. Although our main objective was to compare consumer preferences for environmental versus traditional alternatives, price is an essential attribute given that some/many customers may select ordinary products with lower "environmental quality" because of price and performance considerations or ignorance and disbelief (Ottman, 1998). For this reason, price was incorporated as an attribute. Price levels were determined by taking the fourstate (Indiana, Michigan, Minnesota, and Texas) average price, $\$ 2.99$, for a 4 -inch potted chrysanthemum. The low and high prices were then set at $\$ 0.50$ above $(\$ 3.49)$ and below (\$2.49) the average retail price. The four-state average price was used because the survey was administered in Indiana, Michigan, Minnesota, and Texas. Also, by incorporating price as a product attribute, we can estimate the relative increase or decrease in dollar value associated with varying attribute levels.

There is evidence in the literature that "green" consumers exist within the market. Their presence has also been assumed to bring profits to companies with a record of environmentally friendly practices (Russo and Fouts, 1997). However, there is considerable variation in consumers' attitudes about the environment (Gladwin et al., 1995; Purser et al., 1995). For this reason, we chose to incorporate several attributes that have environmental connotations: material type, carbon footprint, and waste composition of container. Other attributes that could be considered as important to the consumer's purchase decision were held constant, i.e., pot size, flower type and size, and pot color, to minimize variation not accounted for by the attributes identified as most important.

We wanted to evaluate consumer reactions to several biodegradable potting container materials compared with traditional plastic. Wheat starch, rice hulls, and straw were chosen given the interest of these particular containers to the green industry and also given they provided a general representation of what is available on the market. Plastic was used because it is the most accessible in the market and can thereby serve as a control for the biodegradable potting containers. 
Carbon footprint was included given the increased importance both at the producer and consumer end of the marketing channel. The increased importance of carbon footprint can be easily seen by the increasing amount of not only academic research, but also increased media coverage and marketing strategies of businesses attempting to capitalize on claims of carbon footprint savings. As noted by Philip (2008), there has been a shift by consumers to greener food products, which has led businesses to begin to establish measures of a product's carbon footprint so that they can gain a competitive advantage by offering products with lower carbon footprints. One such means of making carbon footprint information available to the consumer is through "carbon labels," as suggested by Pearson and Bailey (2009). To determine consumer preference for and the value of "carbon labels," we compare several different labels, namely "carbon-neutral," "carbon-saving," and "carbon-intense."

The fourth product attribute we included was percent waste composition. This was included to determine if the percentage of the pot made of waste products played any role in the consumer's decision to purchase. Waste composition levels included: " $0 \%$ waste," " $1-49 \%$ waste," and "> or $=50 \%$ waste."

Stimuli. After identifying both the most important attributes and attribute levels, a fractional-factorial design was used to limit the number of stimuli respondents needed to evaluate to improve response rate and reduce participant fatigue. The total number of possible attribute-level combinations was 108 , whereby the fractional-factorial design allowed the actual number of stimuli to be evaluated to be 14 . Products with various combinations of attribute levels were displayed as a picture depicting a 4-inch potted mum with text indicating price, carbon footprint, and waste composition level. Respondents were asked to evaluate each product on a 9-point willingness-to-purchase scale with $9=$ "very likely," $5=$ "somewhat likely," and $1=$ "very unlikely" with 2 to 4 and 6 to 8 serving as intermediate levels. Also, within the directions, respondents were reminded that all the containers were the same size: 4 inches.

The survey was administered through the Internet accessing a sample of $\approx 300$ consumers each from Indiana, Michigan, Minnesota, and Texas, whose average demographic characteristics were reflective of the population at large in those states. The Internet survey was developed by researchers and approved by the university committees involved with research on human subjects. The survey was then implemented by Knowledge Networks during July 2009. Advantages of web-based surveys according to McCullough (1998) are that they are potentially faster to conduct than telephone or face-to-face interviews and generate more accurate information with less human error. Although $74.2 \%$ of the U.S. population has Internet access at work or home (Internet World Stats, 2009), Knowledge Networks pro- vides Internet access to potential respondents without it, thereby eliminating that potential bias.

To eliminate respondents who do not purchase outdoor plants, we asked potential respondents if they had purchased any plants for any type of outdoor use during the last year (since July 2008). If the respondent did not purchase any plants, then the survey ended and the respondent did not proceed to subsequent questions. An answer of "yes" allowed the respondent to finish the rest of the survey. The survey was made up of four parts: 1) types and amounts of plants purchased; 2) conjoint questions; 3) recycling programs offered by the businesses where they purchase the most plants; and 4) personal and household recycling behaviors.

Data analysis. An ordinary least squares regression was used to estimate the partworth utility values for each individual respondent. Individual regression models were used instead of an aggregated model for two reasons. First, aggregating respondents into a single model produces the potential to lose individual effects, which can cause biased estimations and thereby incorrect inferences to be drawn. Fixed or random effects can be used to capture individual effects within an aggregate model, but the model becomes more complex. The second (and most severe) problem is that an aggregated model produces a single set of utility estimates, which makes clustering on preferences (utilities) impossible, which is discussed in detail later. Given the scope of this research, market segmentation through clustering is essential and thereby directly lends itself to individual regression models that take the following form:

$$
\begin{aligned}
R i= & B 0+B 1(P R 2)+B 2(P R 3)+B 3(R H) \\
& +B 4(O P)+B 5(S T W)+B 6(C B S V) \\
& +B 7(C B I N)+B 8(W S 2)+B 9(W S 3) \\
& +e i
\end{aligned}
$$

where $\mathrm{R}$ is the rating of the ith stimuli by the respondent; PR2 $=\$ 2.99 /$ pot; PR3 $=\$ 3.49 /$ pot; $\mathrm{RH}=$ rice hull pot; $\mathrm{OP}=$ wheat pot; STW = straw pot; $\mathrm{CBSV}=$ carbon-saving; $\mathrm{CBIN}=$ carbon-intense; WS2 = waste composition between $1 \%$ and $49 \%$; and $\mathrm{WS} 3=$ waste composition greater or equal to $50 \%$. Base attribute levels included \$2.49/pot, plastic container, carbon-neutral footprint, and made of $0 \%$ waste. Before estimating the individual regressions, each independent variable was effects coded, which means the coefficients are transformed into deviations from the mean (Hair et al., 1998).

It should be noted that because we used a hypothetical conjoint analysis format, there is a potential for bias associated the hypothetical nature of the response format (Murphy et al., 2005). In general non-hypothetical techniques (e.g., experimental auctions) have been used to offset any potential hypothetical biases; however, such surveys that are nonhypothetical may suffer from an additional problem of not being generalizable to the population given the small size of sample participating in the study. Large studies of this type are often infeasible given a large amount of product must be made available for purchase. Furthermore, small sample sizes have the potential to lead to misleading segments if segments can be delineated at all. Given the objective of our article, we believe a hypothetical bias, if present, will have a minimal impact on the overall message associated with the market segments presented with any biases affecting mostly those on the fringe of segments and not the hardcore segment members, which are the target customers for each segment.

After estimating the individual regressions, we proceeded to calculate relative importance values, market segments, and marginal effects associated with each segment. Relative importance values represent the amount of importance, represented as a percentage, an attribute contributes to the consumer's overall buying decision (Hair et al., 1998). For instance, a relative importance of $30 \%$ for the pot type can be interpreted because pot type makes up 30\% of the consumer's buying decision. Relative importance values can be calculated as follows:

$$
R I_{j}=\left(R G_{j} / \sum_{j=1}^{4} R G_{j}\right) * 100
$$

where RI is the relative importance of the jth attribute and $\mathrm{RG}$ is the range of the partworth utilities (coefficients) for attribute $j$.

An important element of using conjoint analysis is the ability to both identify the number of and classify respondents into clusters or market segments. Using cluster analysis, respondents can be placed into clusters by grouping respondents with like part-worth utility (coefficient) estimates into clusters (Green and Helsen, 1989). Numerous criteria exist to identify the number of clusters present within the market, which taken alone may result in varying implications for the number of clusters identified. Therefore, we followed the methodology set forth in Campbell et al. (2004) and used several clustering algorithms, namely Ward, McQuitty, Equal Variance Maximum Likelihood, Flexible Beta, and Complete Linkage (SAS Institute Inc., 1987). The algorithms consistently indicated between five and seven clusters were present. The final determination of the number of segments is subjective; however, Kotler and Armstrong (2001) recommend choosing market segments that are measurable, accessible, substantial, differentiable, and actionable. After examining the segments recommended by the clustering algorithms in accordance with the Kotler and Armstrong guidelines, we chose a seven-segment model because the segments were distinct and allow for direct target marketing. After identifying the optimal number of segments, respondents were assigned to one of the seven clusters through SAS procedures addressed in Campbell et al. (2004).

Of interest was the process by which segments began to decompose as the number 
of segments increased to the optimally defined seven clusters. If a three-clustering solution was used, then the segments would have been straw liking, carbon dislikers, and price/container segment. As the number of clusters was increased, the container/price cluster began to split and fringe respondents were shuffled to other clusters. By five clusters, the environmentally conscious and carbon-sensitive groups were set and did not change with increased cluster levels. Also, the non-discriminating segment was also formed at Cluster 5. An interesting point regarding the non-discriminating segment was that we would suspect that as cluster number increased, the non-discriminating increased clusters would potentially result in fine tuning and fringe non-discriminators would find a new home in a cluster that more aligned with their preferences. However, this was not the case; as the number of clusters increased, the container groups began to splinter into finer segments. For instance, at eight clusters, the straw likers began to fragment into different levels of liking of straw, which produced clusters that were too small for any actionable marketing plan to be implemented.

After assigning respondents to a cluster, a multinomial logit model was used to identify any relationships between segment membership and the explanatory variables. Explanatory variables consisted of demographic and socioeconomic variables, store recycling behaviors, and respondent recycling behaviors and perceptions.

\section{Results and Discussion}

A total of 1113 respondents participated in the survey. However, 279 respondents were eliminated because they did not purchase any plants during year before the survey and another 299 respondents were eliminated as a result of missing responses or lack of variation among the conjoint ratings. The remaining 535 respondents were included in analyses. The 535 responses were collected from participants in four states: Indiana $[\mathrm{n}=133(24.9 \%)]$, Michigan $[\mathrm{n}=$ $141(26.4 \%)]$, Minnesota [ $\mathrm{n}=126(23.6 \%)]$, and Texas $[\mathrm{n}=135(25.2 \%)]$. The sample was $54.4 \%$ female with respondent age ranging from 18 to 92 years with a mean of 47.7 years and a median of 48 years. Over half, $63.6 \%$, were either married or living with a partner. Nine percent of respondents had less than a high school education with $38.3 \%, 21.7 \%$, $24.5 \%$, and $6.5 \%$ having a high school degree, some college, bachelor's/associate's degree, or post-bachelor's degree, respectively. A total of $78.7 \%$ were white, nonHispanic; 9.0\% were black; 8.6\% Hispanic; $3.7 \%$ other, non-Hispanic.

Conjoint results. The part-worth utilities, relative importance values, $R^{2}$, and adjusted $R^{2}$ were calculated for all 535 respondents; however, only the average values are reported in Table 1 for the total and each market segment. Given effects coding was segment would have decreased in size given

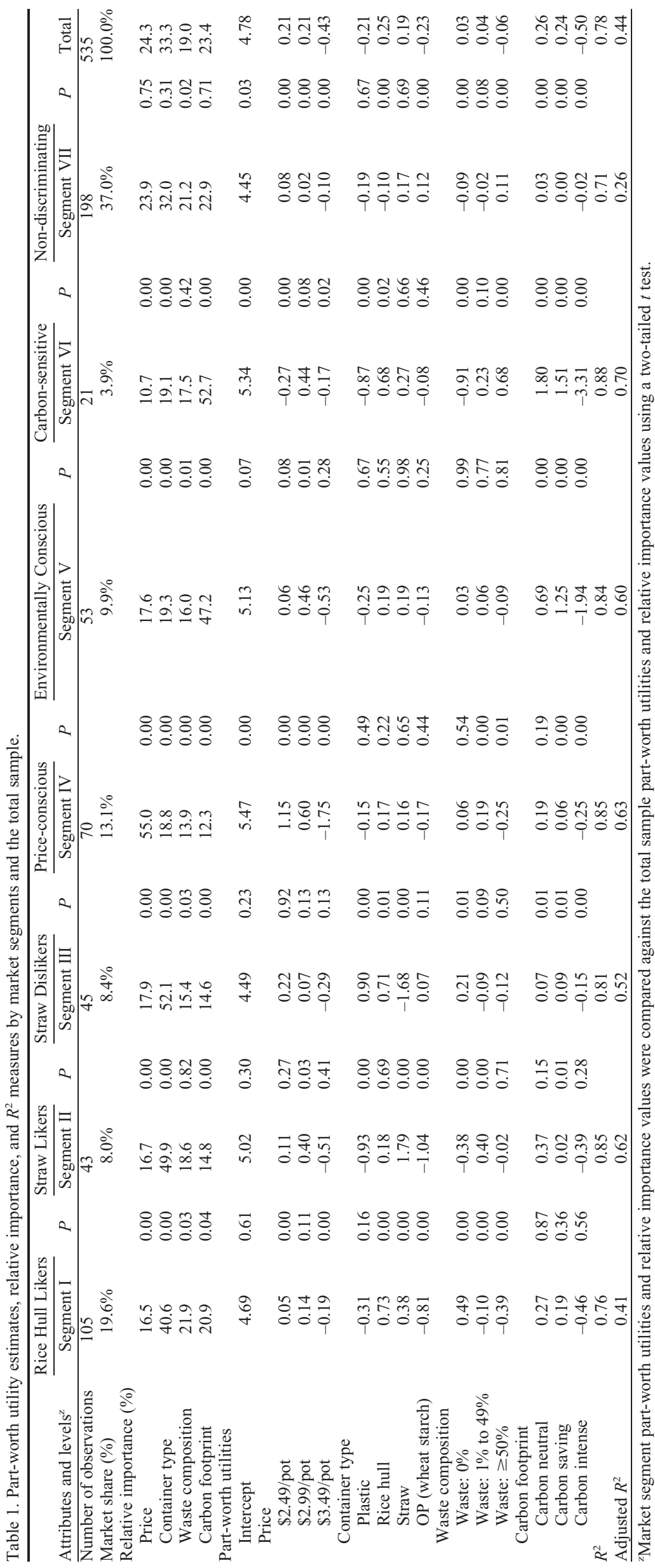


used; the part-worth utilities are interpreted as a change in the mean rating on the 9-point rating scale. Relative importance values can be interpreted as how important each attribute is to the overall buying decision, in which a $100 \%$ relative importance implies that the attribute comprises $100 \%$ of the respondent's buying decision and all other attributes have no effect. Also, for each segment, the market share, number within the segment divided by the total sample, is presented.

For the total sample, relative importance values indicated that container type was the most important attribute comprising 33.3\% of the purchase decision, whereas price, carbon footprint, and waste composition were less important with relative importance values of $24.3 \%, 23.4 \%$, and $19 \%$, respectively. Within the part-worth utilities associated with price, consumers preferred lower prices; \$2.49 and \$2.99 were almost identical, whereas the $\$ 3.49$ price received a large preference decrease. Examination of container type indicates that rice hull and straw were preferred over plastic, whereas the OP container (similar in appearance to plastic) had a negative preference rating of -0.23 . Waste composition only resulted in a small change on the rating scale; however, greater than $49 \%$ waste resulted in a decreased rating of -0.06 . As expected, a carbon footprint label of "intense" resulted in a large rating decrease from the mean of -0.50 , whereas "neutral" and "saving" were almost the same with a 0.26 and 0.24 rating increase, respectively. Surprisingly, carbon-neutral was slightly, but not statistically, higher than carbon-saving.

Although the total sample results provide some interesting results, Bretton-Clark (1992) noted that averaging across a market segments with different utility functions can provide biased results. Furthermore, targeting the whole market can result in businesses wasting valuable resources by marketing a product that might only appeal to a select group of consumers. The average results for each market segment are given in Table 1 with each market segment named according to observed preferences. Market segments included the "Rice Hull Likers," "Straw Likers," "Straw Dislikers," "Price Conscious," "Environmentally Conscious," "Carbon-sensitive," and "Non-discriminating" segments.

Segment I, the "Rice Hull Likers," had a $19.6 \%$ market share. The highest relative importance value for this segment was $40.6 \%$ associated with the container type attribute, which implies that $40.6 \%$ of the respondent's buying decision came from the attribute level, whereas only $16.5 \%$ of the buying decision was dictated by price. So, the type of container was more than twice as important as other individual attributes. Furthermore, the "Rice Hull Likers" segment showed an average rating increase from the overall mean of 0.73 for the rice hull container compared with a -0.31 rating decrease for a plastic potting container, showing their profound preference for this container type. Furthermore, as can be seen in Table 2, $62.9 \%$ of Segment I chose rice hull as their first choice (attribute level with the highest utility, holding all other attribute levels constant). Given these data, a clear preference for this container type helped identify members of this segment.

Segment II, the "Straw Likers" segment, had a market share of $8 \%$. The major distinguishing feature of this segment was the large rating increase associated with straw potting containers. A straw potting container resulted in a 1.79 rating point increase from the mean compared with only a 0.18 increase for the rice hull container. Also of note is that the OP pot resulted in a fairly large decrease of -1.04 from the mean. Interestingly, 95.3\% of respondents chose straw as their first choice with $0 \%$ choosing plastic or OP as their first choice. This small group expressed a clear preference for the container made from straw.

The "Straw Dislikers," Segment III (also with a market share of $8 \%$ ), expressed pref- erences that were the opposite of Segment II. Members of this segment highly discounted straw pots by -1.68 rating points. Also, $0 \%$ of the cluster members chose straw pots as their first choice. An interesting finding within this segment was that the first choice for almost half $(48.9 \%)$ of the segment was the plastic pot. Clearly, they did not like the container made from straw and showed some indications of preferring the plastic container, although they were not strong indications.

Segment IV, "Price Conscious," represented $13.1 \%$ market share. As named, this segment was extremely sensitive to price with lower prices being preferred to higher prices. The $\$ 2.49$ price resulted in a 1.15 rating increase compared with the \$2.99 price, which only garnered a 0.60 rating increase. However, the $\$ 3.49$ price resulted in a large rating decrease of -1.75 rating points. Correspondingly, $75.7 \%$ chose the $\$ 2.49$ price as their first choice with $0 \%$ choosing the $\$ 3.49$ price. So, although this group of consumers did not express a clear preference for any one type of container, their strong preference for lower-priced containers was readily observed.

Segment V was named the "Environmentally Conscious" segment given their dislike of a carbon-intense label. Containers labeled as carbon-intense incurred a -1.94 rating point deduction, whereas carbon-saving resulted in an increased rating of 1.25 points. This segment had a market share of $9.9 \%$ and $73.6 \%$ of segment members expressed carbon-saving as their first choice with $0 \%$ having carbon-intense as their first choice. Again, although no one container material emerged as their preference, they were seeking containers that had low impact (through a low carbon footprint or carbon savings) on the environment.

Segment VI was an interesting market segment. At first glance, this segment appeared to be a more extreme version of the "Environmentally Conscious" segment given their large disdain for a carbon-intense label with the carbon-intense label resulting in a -3.31

Table 2. Percentage of respondents choosing the attribute level as their first choice (highest part-worth utility) by consumer segment. ${ }^{\mathrm{z}}$

\begin{tabular}{|c|c|c|c|c|c|c|c|c|}
\hline \multirow[b]{2}{*}{ Attribute and levels } & \multirow{2}{*}{$\frac{\text { Rice Hull Likers }}{\text { Segment I }}$} & \multirow{2}{*}{\multicolumn{2}{|c|}{$\frac{\text { Straw Likers }}{\text { Segment II }} \frac{\text { Straw Dislikers }}{\text { Segment III }}$}} & \multirow{2}{*}{$\frac{\text { Price-conscious }}{\text { Segment IV }}$} & \multirow{2}{*}{$\frac{\text { Environmentally Conscious }}{\text { Segment V }}$} & \multirow{2}{*}{$\frac{\text { Carbon-sensitive }}{\text { Segment VI }}$} & \multirow{2}{*}{$\frac{\text { Non-discriminating }}{\text { Segment VII }}$} & \multirow{2}{*}{ Total } \\
\hline & & & & & & & & \\
\hline & 105 & 43 & 45 & 70 & 53 & 21 & 198 & 535 \\
\hline \multicolumn{9}{|l|}{ Price } \\
\hline$\$ 2.49 /$ pot & 36.2 & 34.9 & 35.6 & 75.7 & 28.3 & 9.5 & 39.9 & 40.7 \\
\hline$\$ 2.99 /$ pot & 50.5 & 55.8 & 40.0 & 27.1 & 66.0 & 81.0 & 36.4 & 44.5 \\
\hline$\$ 3.49 /$ pot & 13.3 & 11.6 & 24.4 & 0.0 & 5.7 & 9.5 & 25.3 & 15.9 \\
\hline \multicolumn{9}{|l|}{ Container type } \\
\hline Plastic & 10.5 & 0.0 & 48.9 & 18.6 & 13.2 & 0.0 & 16.2 & 15.9 \\
\hline Rice hull & 62.9 & 4.7 & 37.8 & 34.3 & 43.4 & 42.9 & 22.2 & 34.6 \\
\hline Straw & 32.4 & 95.3 & 0.0 & 32.9 & 24.5 & 38.1 & 44.4 & 38.7 \\
\hline OP (wheat starch) & 1.9 & 0.0 & 22.2 & 18.6 & 20.8 & 28.6 & 28.8 & 18.5 \\
\hline \multicolumn{9}{|l|}{ Waste composition } \\
\hline Waste: $0 \%$ & 64.8 & 9.3 & 48.9 & 30.0 & 39.6 & 9.5 & 29.8 & 36.8 \\
\hline Waste: $1 \%$ to $49 \%$ & 25.7 & 58.1 & 31.1 & 45.7 & 32.1 & 23.8 & 34.8 & 35.3 \\
\hline Waste: $\geq 50 \%$ & 9.5 & 32.6 & 20.0 & 24.3 & 28.3 & 66.7 & 35.9 & 28.0 \\
\hline \multicolumn{9}{|l|}{ Carbon footprint } \\
\hline Carbon-neutral & 58.1 & 65.1 & 40.0 & 52.9 & 35.8 & 61.9 & 39.4 & 47.5 \\
\hline Carbon-saving & 46.7 & 34.9 & 37.8 & 37.1 & 73.6 & 38.1 & 35.4 & 41.9 \\
\hline Carbon-intense & 5.7 & 11.6 & 31.1 & 18.6 & 0.0 & 0.0 & 32.8 & 19.3 \\
\hline
\end{tabular}

${ }^{\mathrm{z}}$ Given consumer choice theory, consumers will choose the product with the highest utility given it is in their budget constraint. 
rating decrease. If this segment was more environmentally conscious than Segment V, then we would expect carbon-saving to be preferred to carbon-neutral. However, from the part-worth utilities, we saw that carbonneutral actually incurred a higher rating compared with carbon-saving. We expected that carbon-intense containers were not chosen, which was confirmed given $0 \%$ chose carbon-intense containers as their first choice. However, $73.6 \%$ of Segment V members chose carbon-saving as their first choice compared with only $38.1 \%$ of Segment VI. After evaluating the choices associated with Segment VI and the marginal effects, discussed subsequently, we believe this segment is most likely a mixture of extreme environmentalists along with consumers that perceive carbon intensity to be bad and therefore represents a product attribute that is unwanted; therefore, we refer to them as "carbon-sensitive."

Marginal effects. A multinomial logit model was used after each respondent was placed into a segment. From the multinomial logit model, the marginal effects were calculated to develop consumer profiles. Consumer profiles associated with each market segment allow businesses to more efficiently target specific segments by allowing for direct marketing campaigns that emphasize specific characteristics that are preferred by the segment of interest. Marginal effects for the demographic and socioeconomic charac- teristics can be found in Table 3, whereas the marginal effects associated with recycling views and behaviors can be found in Table 4.

"Rice Hull Likers" who comprised Segment I were more likely to be younger consumers with higher incomes living in a non-metro area with fewer adults per household (18 years of age or older). Interpretation of the results varies depending on the type of variable of interest, e.g., continuous or dummy. For example, as age increases by one unit from the mean, there is a $0.07 \%$ decrease in the probability of a participant being a member of Segment I. This appears to be a small change; however, given a change of several years from the mean, the decrease in the probability of segment membership could be substantial. With regard to a dummy variable such as metro area, the interpretation is that living in a metro area, as compared with a non-metro area, results in a $-14.6 \%$ decrease in the probability of a participant being a member of Segment I. Of note is that as income increases, the probability of being in Segment I increases at a higher rate. For instance, a household with income between $\$ 20,000$ and $\$ 49,000$ is $15.9 \%$ more likely to be in this segment compared with households with incomes below $\$ 20,000$, whereas households with $\$ 50,000$ to $\$ 74,000$ and greater than or equal to $\$ 75,000$ are $23.5 \%$ and $25.7 \%$ more likely to be in Segment I, respectively.
Examination of Table 4 shows that the "Rice Hull Likers" have a distinct consumer profile associated with purchasing and recycling behaviors and beliefs that can be used by the Green industry. For instance, respondents who purchased indoor flowering plants were $16.3 \%$ more likely to be members of this segment, whereas respondents who purchased flowering shrubs were $-9.9 \%$ less likely to be a member. Also, members of this segment are less likely to have interest in purchasing sustainable bedding plants. However, they have an increased interest in plants grown in compostable pots. Also of note is that consumers display increased agreement that recycling pots are more important than biodegradable pots and are $10.6 \%$ less likely to be members of this segment. When shown a statement (see footnotes in Table 4) regarding a simple definition of what defines carbon-saving and carbon-intensive, consumers who agreed with the statements were $8.1 \%$ and $8.5 \%$ less likely to be in this segment, respectively.

Examination of the marginal effects associated with Segment II, "Straw Likers," indicates that blacks and Hispanics are less likely to be members of this group nor are consumers who are married or living with a partner. Furthermore, with an increased number of adults within a household or a participant living in a metro area resulted in an increased probability of being included in this segment. Also, consumers who

Table 3. Marginal probabilities for demographic and socioeconomic variables by consumer segment with respect to a vector of explanatory variables (computed at the mean)

\begin{tabular}{|c|c|c|c|c|c|c|c|c|c|c|c|c|c|c|}
\hline \multirow[b]{3}{*}{ Variable $^{z, y}$} & \multicolumn{14}{|c|}{ Marginal probabilities of membership in each segment } \\
\hline & \multirow{2}{*}{$\begin{array}{c}\text { Probability } \\
\text { Segment I } \\
\text { Coefficient }\end{array}$} & \multirow[b]{2}{*}{$P$} & \multirow{2}{*}{$\begin{array}{l}\text { Probability } \\
\text { Segment II } \\
\text { Coefficient }\end{array}$} & \multirow[b]{2}{*}{$P$} & \multirow{2}{*}{$\begin{array}{l}\text { Probability } \\
\text { Segment III } \\
\text { Coefficient }\end{array}$} & \multirow[b]{2}{*}{$P$} & \multirow{2}{*}{$\begin{array}{l}\text { Probability } \\
\text { Segment IV } \\
\text { Coefficient }\end{array}$} & \multirow[b]{2}{*}{$P$} & \multirow{2}{*}{$\begin{array}{l}\text { Probability } \\
\text { Segment V } \\
\text { Coefficient }\end{array}$} & \multirow[b]{2}{*}{$P$} & \multirow{2}{*}{$\begin{array}{l}\text { Probability } \\
\text { Segment VI } \\
\text { Coefficient }\end{array}$} & \multicolumn{3}{|c|}{$\begin{array}{c}\text { Probability } \\
\text { Segment VII }\end{array}$} \\
\hline & & & & & & & & & & & & $P$ & Coefficient & $P$ \\
\hline Age (years) & -0.007 & 0.00 & 0.000 & 0.95 & -0.002 & 0.05 & 0.003 & 0.07 & -0.001 & 0.10 & 0.000 & 0.57 & 0.007 & 0.00 \\
\hline \multicolumn{15}{|l|}{ Education } \\
\hline High school g & 0.001 & 0.99 & -0.004 & 0.89 & -0.026 & 0.37 & 0.221 & 0.07 & 0.083 & 0.22 & 0.000 & 0.95 & -0.274 & 0.01 \\
\hline Some & 0.011 & 0.91 & -0.018 & 0.61 & -0.055 & 0.01 & .139 & 0.33 & 0.037 & 0.60 & -0.001 & 0.69 & -0.113 & 0.42 \\
\hline \multicolumn{15}{|l|}{ Race } \\
\hline White & 0.111 & 0.32 & -0.010 & 0.84 & & 0.09 & 0.064 & 0.25 & 0.035 & 0.48 & -0.001 & 0.76 & -0.268 & 0.08 \\
\hline Bla & .193 & 0.48 & -0.055 & 0.01 & & 0.55 & -0.05 & 0.31 & & 0.57 & -0.001 & 0.64 & -0.420 & 0.00 \\
\hline & 038 & 0.83 & -0.062 & 0.00 & 0.056 & 0.79 & 0.0 & 0.64 & 0.0 & 0.59 & -0.001 & 0.66 & -0.199 & 0.34 \\
\hline Household h & -0.029 & 0.68 & -0.012 & 0.74 & 0.034 & 0.07 & -0.070 & 0.30 & 0.014 & 0.59 & -0.013 & 0.43 & 0.076 & 0.41 \\
\hline \multicolumn{15}{|l|}{ Income } \\
\hline$\$ 20,000$ & 0.159 & 0.09 & 0.124 & 0.17 & -0.064 & 0.02 & 0.007 & 0.88 & 0.085 & 0.13 & -0.002 & 0.60 & -0.309 & 0.00 \\
\hline $\begin{array}{l}\text { Housing } \\
\qquad(1=\text { detached structure })\end{array}$ & -0.054 & 0.41 & -0.058 & 0.30 & 0.026 & 0.18 & -0.022 & 0.66 & 0.035 & 0.17 & 0.000 & 0.90 & 0.073 & 0.39 \\
\hline \multicolumn{15}{|l|}{ Household makeup } \\
\hline & 0.059 & 0.03 & 0.001 & 0.95 & & 0.33 & & 0.14 & -0.015 & 0.38 & -0.001 & 0.68 & -0.081 & 0.04 \\
\hline $110-1 /$ years & -0.056 & 0.24 & 0.019 & 0.28 & & 0.24 & & 0.06 & & 0.09 & 0.001 & 0.47 & -0.066 & 0.23 \\
\hline Number $\geq 18$ years & -0.067 & 0.08 & 0.037 & 0.09 & 0.013 & 0.32 & -0.004 & 0.84 & -0.009 & 0.60 & 0.000 & 0.67 & 0.030 & 0.51 \\
\hline Employed $(1=$ yes $)$ & -0.080 & 0.15 & -0.051 & 0.06 & -0.026 & 0.28 & -0.025 & 0.51 & -0.015 & 0.51 & 0.002 & 0.59 & 0.196 & 0.00 \\
\hline MSA $(1=$ metro $)$ & -0.148 & 0.06 & 0.044 & 0.01 & 0.009 & 0.66 & -0.026 & 0.54 & -0.025 & 0.46 & 0.002 & 0.62 & 0.145 & 0.06 \\
\hline \multicolumn{15}{|l|}{ State } \\
\hline Minnesc & -0.068 & 0.27 & 0.053 & 0.37 & & 0.39 & -0.045 & 0.24 & & 0.10 & 0.000 & 0.86 & -0.081 & 0.38 \\
\hline Indiana & -0.074 & 0.24 & 0.055 & 0.31 & 0.007 & 0.82 & -0.025 & 0.50 & -0.006 & 0.85 & 0.001 & 0.73 & 0.042 & 0.63 \\
\hline Michigan & -0.137 & 0.01 & 0.018 & 0.62 & 0.074 & 0.14 & -0.055 & 0.10 & 0.050 & 0.30 & 0.000 & 0.84 & 0.050 & 0.57 \\
\hline
\end{tabular}

${ }^{\mathrm{z} B a s e}$ categories are: female, not a high school graduate, other race, not household head, income less than $\$ 20,000$, not married or have partner, housing not detached, not employed, not MSA area, and Texas.

${ }^{\mathrm{y} B o l d}$ indicates significance at the 0.1 level, but $P$ values are also given. 
Table 4. Marginal probabilities for purchasing and recycling behaviors and beliefs by consumer segment with respect to a vector of explanatory variables (computed at the mean).

probabilities of membership in each segment

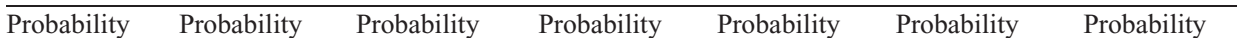

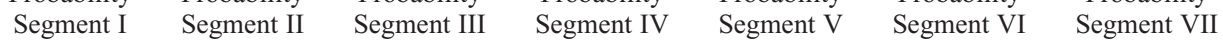

Variable $\mathrm{e}^{\mathrm{z}, \mathrm{y}, \mathrm{x}}$

Coefficient $P$ Coefficient $P$ Coefficient $P$ Coefficient $P$ Coefficient $P$ Coefficient $P$ Coefficient $P$

Expenditures of lawn/garden products?

Dollars: $1-25$

Dollars: 26-50

Dollars: $51-100$

Dollars: $101-150$

Dollars: $151-200$

Dollars: 201-250

Dollars: $\geq 250$

Types of plants purchased?

Flowering annuals

Flowering perennials

Herbs/vegetables

Flowering shrubs

Trees

Indoor flowering plants

Where are plants purchased?

Mass merchandiser

Home improvement center

Number of trips made?

Heard of term sustainability?

Yes

No

Interest in purchasing following plant types? ${ }^{\mathrm{w}}$

Conventional bedding plants

Organic bedding plants

Sustainable bedding plants

Locally produced bedding plants

Grown in organic fertilizer

From energy-efficient greenhouse

Grown in biodegradable pots

Grown in compostable pots

Grown in recyclable pots

Coeffic

Reason to purchase environmentally friendly pla

These plants are environmentally friendly

$\begin{array}{rrrr}-0.029 & 0.74 & 0.149 & 0.26 \\ 0.087 & 0.45 & 0.114 & 0.36 \\ 0.046 & 0.66 & 0.084 & 0.42 \\ -0.004 & 0.97 & 0.106 & 0.38 \\ -0.029 & 0.80 & 0.063 & 0.55 \\ -0.016 & 0.89 & 0.129 & 0.47 \\ -0.001 & 0.99 & 0.059 & 0.55\end{array}$

$\begin{array}{llll}0.062 & 0.39 & -0.021 & 0.66\end{array}$

$\begin{array}{llll}0.065 & 0.36 & 0.001 & 0.99\end{array}$

$\begin{array}{llll}0.037 & 0.53 & -0.064 & 0.11\end{array}$

$\begin{array}{llll}0.032 & 0.61 & \mathbf{- 0 . 0 7 5} & 0.07\end{array}$

$\begin{array}{llll}0.017 & 0.79 & \mathbf{- 0 . 0 7 8} & 0.03\end{array}$

$\begin{array}{llll}0.068 & 0.44 & \mathbf{- 0 . 0 6 4} & 0.10 \\ 0.013 & 0.80 & -0.059 & 0.25\end{array}$

$\begin{array}{llll}0.035 & 0.56 & 0.000 & 0.97\end{array}$

$\begin{array}{llll}0.070 & 0.42 & -0.001 & 0.61\end{array}$

$\begin{array}{rrrr}0.026 & 0.64 & 0.000 & 0.90\end{array}$

$\begin{array}{llll}-0.011 & 0.78 & -0.001 & 0.62\end{array}$

$\begin{array}{llll}-0.001 & 0.99 & -0.001 & 0.64\end{array}$

$\begin{array}{ll}0.000 & 0.92\end{array}$

$\begin{array}{ll}-0.043 & 0.27\end{array}$

$\begin{array}{ll}0.003 & 0.77\end{array}$

$\begin{array}{lllll}0.079 & 0.15 & 0.006 & 0.78 & -0.0\end{array}$

$\begin{array}{llll}0.046 & 0.42 & -0.007 & 0.80\end{array}$

$\begin{array}{llll}0.026 & 0.61 & 0.018 & 0.43\end{array}$

$\begin{array}{llll}\mathbf{- 0 . 0 9 9} & 0.09 & \mathbf{0 . 0 8 8} & 0.04\end{array}$

\begin{tabular}{llll}
-0.083 & 0.18 & 0.011 & 0.72 \\
\hline
\end{tabular}

$\begin{array}{llll}\mathbf{0 . 1 6 3} & 0.01 & -0.020 & 0.33\end{array}$

$\mathbf{- 0 . 0 7 6} \quad 0.02$

$0.012 \quad 0.55$

$0.023 \quad 0.56$

$\begin{array}{ll}-0.001 & 0.98\end{array}$

$\begin{array}{ll}-0.031 & 0.13\end{array}$

$\begin{array}{ll}-0.042 & 0.25\end{array}$

$\begin{array}{rr}-0.024 & 0.44\end{array}$

$\begin{array}{llll}0.016 & 0.61 & -0.003 & 0.95\end{array}$

$\begin{array}{llll}0.002 & 0.94 & -0.010 & 0.83\end{array}$

$\begin{array}{lllll}\mathbf{0 . 0 8 3} & 0.01 & -0.008 & 0.83\end{array}$

$\begin{array}{lll}0.031 & 0.43\end{array}$

$0.002 \quad 0.56$

$\begin{array}{ll}0.001 & 0.67\end{array}$

$\begin{array}{ll}0.000 & 0.99\end{array}$

$\begin{array}{ll}0.001 & 0.52\end{array}$

$\mathbf{- 0 . 0 4 6} 0.03$

$0.029 \quad 0.30$

$-0.00$

$0.000 \quad 0.79$

$\begin{array}{llll}0.079 & 0.25 & 0.041 & 0.26\end{array}$

$\begin{array}{ll}0.024 & 0.35\end{array}$

\section{$\begin{array}{ll}0.029 & 0.53\end{array}$}

$0.000 \quad 1.00$

$\begin{array}{ll}0.005 & 0.55\end{array}$

$\begin{array}{llll}0.026 & 0.64 & 0.010 & 0.72\end{array}$

$\begin{array}{ll}0.026 & 0.38\end{array}$

$0.012 \quad 0.76$

$\begin{array}{ll}0.018 & 0.55\end{array}$

$\begin{array}{lll}\mathbf{0 . 0 0 9} & 0.02\end{array}$

$\begin{array}{llll}0.049 & 0.36 & -0.016 & 0.53\end{array}$

$-0.002 \quad 0.44$

$\begin{array}{ll}\mathbf{0 . 0 6 0} & 0.03\end{array}$

$\begin{array}{ll}0.057 & 0.27\end{array}$

$\begin{array}{ll}\mathbf{- 0 . 0 6 5} & 0.09\end{array}$

$\mathbf{- 0 . 0 8 2} 0.01$

$\begin{array}{ll}0.002 & 0.71 \\ 0.000 & 0.57\end{array}$

$\begin{array}{llll}-0.061 & 0.28 & 0.005 & 0.88\end{array}$

$\begin{array}{llll}0.031 & 0.16 & -0.014 & 0.15\end{array}$

$\begin{array}{ll}-0.005 & 0.51\end{array}$

$\begin{array}{llll}-0.005 & 0.86 & -0.005 & 0.64\end{array}$

$\begin{array}{lllll}\mathbf{0} & \mathbf{0 . 0 6 7} & 0.01 & -0.003 & 0.80\end{array}$

$\begin{array}{llll}-0.040 & 0.14 & 0.010 & 0.36\end{array}$

$\begin{array}{llll}0.012 & 0.69 & 0.018 & 0.14\end{array}$

$\begin{array}{llll}0.024 & 0.32 & -0.010 & 0.26\end{array}$

$\begin{array}{llll}0.011 & 0.71 & -0.002 & 0.91\end{array}$

$\begin{array}{lllll}\mathbf{0 . 0 5 6} & 0.04 & 0.007 & 0.45\end{array}$

$\begin{array}{llll}-0.032 & 0.15 & 0.009 & 0.28\end{array}$

$-0.012 \quad 0.23$

$0.000 \quad 0.96$

$\mathbf{0 . 0 1 8} 0.03$

$\begin{array}{ll}-0.001 & 0.92\end{array}$

$0.002 \quad 0.83$

$\begin{array}{ll}-0.013 & 0.23\end{array}$

$\begin{array}{ll}-0.013 & 0.11\end{array}$

$\mathbf{0 . 0 2 7} 0.00$

$\begin{array}{ll}-0.048 & 0.13\end{array}$

$\mathbf{0 . 0 2 7} \quad 0.06$

$\mathbf{- 0 . 0 4 4} 0.04$

$0.001 \quad 0.69$

$\begin{array}{ll}0.016 & 0.32\end{array}$

$-0.008 \quad 0.40$

$\begin{array}{ll}-0.002 & 0.44\end{array}$

$\mathbf{0 . 0 3 1} 0.04$

$\begin{array}{ll}0.012 \quad 0.36 \\ 0.000 & 1.00\end{array}$

$\begin{array}{ll}-0.001 & 0.59\end{array}$

$\begin{array}{ll}0.000 & 0.85\end{array}$

$\begin{array}{ll}0.000 & 0.82\end{array}$

$\mathbf{0 . 0 3 1} 0.08$

$\begin{array}{ll}0.000 & 1.00\end{array}$

$\begin{array}{llll}-0.005 & 0.69 & 0.010 & 0.38\end{array}$

$\begin{array}{llll}-0.018 & 0.21 & 0.018 & 0.19\end{array}$

$0.000 \quad 0.90$

$\begin{array}{lll}0.001 & 0.68\end{array}$

$\begin{array}{ll}0.000 & 0.70\end{array}$

$\begin{array}{lll}0.000 & 0.73\end{array}$

$0.000 \quad 0.84$

$0.006 \quad 0.62$

$0.000 \quad 0.95$

$\begin{array}{ll}-0.012 & 0.41\end{array}$

$0.004 \quad 0.73$

$\begin{array}{ll}-0.085 & 0.12\end{array}$

$\begin{array}{ll}0.000 & 1.00\end{array}$

$-0.005 \quad 0.83$

$\begin{array}{lll}\mathbf{0 . 0 9 5} & 0.07\end{array}$

$0.000 \quad 0.74$

$0.022 \quad 0.42$

$\begin{array}{ll}0.000 & 0.99\end{array}$

$\begin{array}{ll}-0.012 & 0.59\end{array}$

$-0.052 \quad 0.09$

$\begin{array}{ll}-0.013 & 0.67\end{array}$

$\begin{array}{ll}0.001 & 0.53\end{array}$

$\begin{array}{ll}0.000 & 0.99\end{array}$

Sorting household waste is too inconvenient ${ }^{v}$

Recycling pots more important ${ }^{\mathrm{v}}$

$\begin{array}{llll}\mathbf{- 0 . 0 4 0} & 0.09 & 0.000 & 1.00 \\ \mathbf{- 0 . 1 0 6} & 0.00 & \mathbf{0 . 0 4 5} & 0.00\end{array}$

$\mathbf{0 . 0 1 9} 0.05$

$\mathbf{- 0 . 0 6 1} 0.06$

$\begin{array}{ll}-0.021 & 0.47\end{array}$

$\begin{array}{ll}0.015 & 0.23\end{array}$

$\begin{array}{ll}-\mathbf{0 . 0 4 2} & 0.06 \\ -0.005 & 0.76\end{array}$

$\begin{array}{ll}-0.022 & 0.17\end{array}$

$\begin{array}{ll}0.001 & 0.55\end{array}$

$\begin{array}{llllll}0.005 & 0.76 & \mathbf{- 0 . 0 2 8} & 0.02 & -0.001 & 0.66\end{array}$

$0.010 \quad 0.48$

$\begin{array}{ll}0.004 & 0.85\end{array}$

$0.000 \quad 0.63$

$\begin{array}{lllll}-\mathbf{0} & 0.035 & 0.05 & -0.001 & 0.61\end{array}$

$\begin{array}{ll}-\mathbf{0 . 1 9 5} & 0.08\end{array}$

$\mathbf{- 0 . 3 3 5} \quad 0.00$

$\begin{array}{ll}-0.130 & 0.28\end{array}$

$\begin{array}{ll}-0.048 & 0.72\end{array}$

$0.029 \quad 0.85$

$\begin{array}{ll}0.133 & 0.43\end{array}$

$0.027 \quad 0.85$

$-0.033 \quad 0.65$

$0.013 \quad 0.86$

$\begin{array}{ll}0.019 & 0.77\end{array}$

$-0.035 \quad 0.67$

$\begin{array}{ll}0.126 & 0.11\end{array}$

$\mathbf{- 0 . 2 4 7} \quad 0.00$

How often do you recycle containers?

Sometimes

Usual/always

How often do you recycle plastic tags?

Sometimes

Usual/always

Agree with carbon-saving definition? $?^{\mathrm{v}, \mathrm{u}}$

Agree with carbon-intensive definition? ? $^{\mathrm{v}, \mathrm{t}}$

$\begin{array}{llll}-0.024 & 0.68 & -0.015 & 0.58\end{array}$

$\begin{array}{llll}-0.073 & 0.29 & \mathbf{- 0 . 0 6 0} & 0.02\end{array}$

$-0.010 \quad 0.68$

$\begin{array}{ll}0.032 & 0.39\end{array}$

$0.003 \quad 0.95$

$\begin{array}{ll}0.044 & 0.39\end{array}$

$\begin{array}{llll}0.000 & 0.99 & -0.001 & 0.57\end{array}$

$\begin{array}{llll}0.004 & 0.89 & -0.001 & 0.57\end{array}$

$\mathbf{- 0 . 1 7 8} \quad 0.02$

$-0.093 \quad 0.16$

$\mathbf{- 0 . 0 2 0} \quad 0.06$

$0.053 \quad 0.45$

$0.094 \quad 0.23$

$\begin{array}{llllllll}0.028 & 0.71 & -0.033 & 0.19 & 0.052 & 0.23 & \mathbf{- 0 . 0 5 3} & 0.09\end{array}$

$\begin{array}{llllllll}0.046 & 0.61 & 0.013 & 0.75 & -0.003 & 0.92 & \mathbf{- 0 . 0 6 2} & 0.08\end{array}$

$\begin{array}{llll}0.055 & 0.28 & 0.000 & 0.90\end{array}$

$\begin{array}{llll}0.014 & 0.74 & 0.000 & 0.82\end{array}$

$\begin{array}{llll}\mathbf{0 . 0 5 3} & 0.02 & 0.000 & 0.85\end{array}$

$\begin{array}{ll}-0.031 & 0.23\end{array}$

$-0.005 \quad 0.87$

$0.038 \quad 0.22$

$-0.020 \quad 0.53$

$0.004 \quad 0.92$

$-0.020 \quad 0.49$

$0.005 \quad 0.89$

$\mathbf{- 0 . 0 5 2} \quad 0.10$

$0.005 \quad 0.87$

$\begin{array}{llllllll}\mathbf{- 0 . 0 8 1} & 0.02 & -0.003 & 0.85 & -0.005 & 0.67 & 0.039 & 0.15\end{array}$

$\begin{array}{llll}0.018 & 0.26 & 0.000 & 0.67\end{array}$

$\mathbf{0 . 1 5 5} 0.06$

$\begin{array}{ll}0.168 & 0.02\end{array}$

$\begin{array}{ll}0.063 & 0.15\end{array}$

$\mathbf{0 . 0 5 6} 0.08$

$0.030 \quad 0.46$

$\mathbf{0 . 0 8 1} 0.06$

$0.048 \quad 0.55$

$0.053 \quad 0.56$

$\begin{array}{llllllll}\mathbf{- 0 . 0 8 5} & 0.01 & -0.015 & 0.40 & \mathbf{0 . 0 2 2} & 0.10 & 0.008 & 0.74\end{array}$

${ }^{2}$ Base categories not yes/no answer include: dollar expenditures $=0$, in which purchase $=$ other store type, heard of sustainability $=$ not sure, reason to purchase environmentally friendly plants $=$ other, how often buy plastic containers $=$ never, how often buy recycled plastic tags $=$ never.

${ }^{\mathrm{y}}$ Bold indicates significance at the 0.1 level, but $P$ values are also given.

'Survey question regarding expenditures and purchases were for the last year (July 2008 to July 2009).

"The interest in purchasing question was on a $1-7$ scale in which $1=$ "low interest" and $5=$ "high interest."

"A $1-5$ scale was used in which $1=$ "strongly disagree" and $5=$ "strongly agree."

"The survey asked for agreement with the following statement: A carbon-saving footprint for a product means it takes less energy to make or ship the product to where I buy it.

'The survey asked for agreement with the following statement: A carbon-intensive footprint for a product means it takes a lot of energy to make or ship the product to where I buy it.

purchased flowering shrubs and usually or always recycle their plastic containers are $8.8 \%$ and $6 \%$ more likely to be in this segment, respectively.

Taking a more in-depth look at Segment III, "Straw Dislikers," tended to be less educated as demonstrated by the negative signs (and significance levels) associated with the education levels above "no high school degree." Increased incomes also resulted in a lower probability of segment membership. In regard to recycling views and behaviors in Table 4, we see that this segment is most likely made up of persons who do not purchase flowering annuals but do purchase indoor flowering plants. This segment is also more likely to agree that sorting household waste is too inconvenient, which implies they are less likely to be active in recycling efforts. They do, however, have an interest in locally produced bedding plants and plants grown in recyclable pots.
The price-conscious segment fits many a priori notions. For instance, members of this segment tended to have a higher education level and be married. Furthermore, higher expenditures on outdoor lawn/garden products results in a lower probability of being in this segment for consumers spending $\$ 101$ to $\$ 250$. We also see that having heard of sustainability results in a $7.2 \%$ decrease compared with those who are not sure about the term. Consumers within this segment are 
also less likely to purchase environmentally plants as a result of feeling good about helping the environment or because the plants are environmentally friendly. Furthermore, this segment is more likely to have interest in conventional, sustainable, and locally produced bedding plants.

The "Environmentally Conscious" segment exhibited concern about the environment. They do not have a concise demographic profile other than being more likely to be younger consumers, but they do have a specific set of recycling views that set them apart. For instance, they are more likely to disagree that sorting household waste is too inconvenient; however, they generally do not control if a package is made of recycled material. This segment is a viable market segment given less of a carbon footprint will result in higher product liking, and thereby purchases, for these consumers. Direct marketing strategies to target this group of consumers is quite simple offer products that have a small carbon footprint.

A consumer profile for the "Carbonsensitive" segment could not be well defined because no statistically significant difference was found within the marginal effects. This is most likely a direct effect of the small size of the market segment, but a mixture of varying beliefs and/or knowledge regarding carbonintensive footprints could also play a role. Members of this segment did not converge with the previous segment until a four-cluster solution, which means that they are not as similar to environmentally conscious as one might expect. Again, like with the previous segment, a means by which to target this group is to offer a non-carbon-intense labeled product. Future research should take a more in-depth look at this segment to better understand the makeup of this segment.

The final segment is the "Non-discriminating" segment given this group does not have any distinguishable preferences that can be easily targeted by a marketing campaign. In general, this segment was made up of older consumers of lower education and incomes that live in a metro area. They are $24.7 \%$ less likely to purchase indoor flowering plants and $17.8 \%$ less likely to list "mass merchandiser" as the place where a majority of their outdoor plants were purchased. Of note is that for each increased trip to their "favorite" horticultural store, they are $2 \%$ less likely to be in this segment. They are also more likely to agree that sorting household waste is too inconvenient.

\section{Conclusions}

Over the last decade, the Green industry has made significant strides to offer more environmentally beneficial alternatives, whether it is a biodegradable potting container, increased waste composition, or even a reduction in the carbon footprint associated with old or new products. However, little is known about how traditional product attributes compare with newer attributes that may be more environmentally friendly. Our study bridges this gap by allowing for not only a better understanding of consumer preferences, but we also identify several distinct consumer segments that can allow producers/ businesses to more efficiently use their resources to offer specific product attributes to those that value them the most.

Our analysis identified seven market segments and corresponding consumer profiles. The "Rice Hull Likers" liked the rice hull pots and tended to be younger, higher-income consumers with fewer adults in the household that live in a non-metro area. They also tend to purchase indoor flowering plants and have less interest in sustainable bedding plants. As the name suggests, this consumer segment will be more willing to purchase the rice hull pot compared with the other pots holding everything else constant. To capitalize on this segment, businesses should associate rice hull pots, perhaps mainly for flowering indoor potted plants, with a younger, higherincome customer image in non-metro outlets.

To target "Straw Likers," straw pots should be marketed in metro areas in stores that have fewer black and Hispanic shoppers. However, straw pots should not be targeted at younger, less educated consumers given this demographic is more likely to be in the "Straw Dislikers" segment.

Direct marketing potting containers toward the "Price-conscious" segment is highly dependent on the cost of production of the pot. To achieve the all important first sell, a potting container is going to have to be the cheapest on the market given there are not huge rating premiums or discounts associated with the various potting containers holding all other attributes constant. Unless potting containers can compete on price, they should be marketed in areas with more single and less educated consumers that spend more on outdoor lawn/garden products.

The "Environmentally Conscious" segment tends to be those most likely to recycle household waste. The means to target the "Environmentally Conscious" as well as the "Carbon-sensitive" is by offering non-carbon-intense products, which results in increased product liking holding all else constant. However, the "Environmentally Conscious" group will perceive a greater benefit to the carbon-saving compared with the carbon-neutral label. On the other hand, the "Carbon-sensitive" will not reward the carbon-saving label, which is one of the reasons why we perceive these groups as different segments. Furthermore, targeting of the "Environmentally Conscious" segment are less concerned with pot type and waste level, whereas the "Carbon-sensitive" segment can find increased liking through rice hull and higher waste composition products.

The "Non-discriminating" segment does not have any product attributes that will allow for easy target marketing, thereby implementing the strategies for the other six segments will bring in sales from this segment.

As a secondary benefit of this research, container manufacturers and distributors (as well as plant producers and retailers) now have a better understanding of the diversity of consumers to which they market products. Most lack the resources and ability to conduct this type of research on their own; thus, the study has provided them with some consumer insight they would not have otherwise.

Additionally, visibility of containers made from non-virgin plastic continues to increase. At a minimum, the study helped to improve the awareness among consumers and industry professionals with regard to the number and type of alternative container materials available on the market today or coming to the market in the near future.

In terms of merchandising strategies for biodegradable containers, industry firms need to be consistent with their message, communicating information about biodegradable containers across all media, including web sites, catalogs, consumer advertising, and store shelves. Additionally, the value proposition of these products has to be clear and devoid of greenwashing (the misrepresentation of product attributes). Consumers have demonstrated a reluctance to purchase low-quality products, even if they do have green attributes. They must perform as well or better than non-green competing products. Lastly, understanding why customers are buying green products and the premiums they are willing to pay for more sustainable options will influence pricing strategies for industry firms. If the point of differentiation of biodegradable containers can be successfully communicated to end users (making the demand for these products more inelastic), total revenue for industry firms will increase through any price premiums, even if total units sold decreases.

The need for future research regarding consumer preferences for many aspects about ornamental plants that relate to the environment is high. Future research is needed to determine monetary willingness to pay for various potting containers and carbon footprint levels to determine if it is feasible to produce/ market them. Additional research may link consumer preferences for different types of production systems (e.g., conventional, sustainable, and organic) to container preferences. Market simulations are also needed to better understand how new product introductions will affect current market conditions.

\section{Literature Cited}

Baker, G.A. 1998. Strategic implications of consumer food safety preferences - consumer concerns and willingness-to-pay. Intl. Food Agribus. Mgt. Rev. 1:451-463.

Behe, B.K. 2006. Conjoint analysis reveals consumers prefer long, thin asparagus spears. HortScience 41:1259-1262.

Behe, B.K., R. Nelson, S. Barton, C. Hall, C. Safley, and S. Turner. 1999. Consumer preferences for geranium flower color, leaf variegation and price. HortScience 34:740-742.

Behe, B.K., R.M. Walden, M.W. Duck, B.M. Cregg, K.M. Kelley, and R.D. Lineberger. 2005a. Consumer preferences for tabletop Christmas trees. HortScience 40:409-412.

Behe, B., J. Hardy, S. Barton, J. Brooker, T. Fernandez, C. Hall, J. Hicks, R. Hinson, P. Knight, R. McNiel, T. Page, B. Rowe, C. 
Safley, and R. Schutzki. 2005b. Landscape plant material, size, and design sophistication increase perceived home value. J. Env. Hort. 23:127-133.

Biogro-Pots: Eco Friendly. 2007. 21 Aug. 2009. $<$ http://www.biogrow.co.nz/>.

Bretton-Clark. 1992. Conjoint analyzer, Version 3. Bretton-Clark, Morrsitown, NJ.

Campbell, B.L., R.G. Nelson, R.C. Ebel, and W.A. Dozier. 2006. Mandarin attributes preferred by consumers in grocery stores. HortScience 41:664-670.

Campbell, B.L., R.G. Nelson, R.C. Ebel, W.A. Dozier, J.L. Adrian, and B.R. Hockema. 2004. Fruit quality characteristics that affect consumer preferences for Satsuma mandarins. HortScience 39:1664-1669.

Engel, U. and M. Potschke. 1998. Willingness to pay for the environment: Social structure, value orientations and environmental behavior in a multilevel perspective. Innovation 11:315332.

Environmental Protection Agency. 2005. Municipal solid waste in the United States. 26 June 2009. $<$ http://www.epa.gov/osw/nonhaz/municipal/pubs/ msw07-rpt.pdf>.

Environmental Protection Agency. 2007. Municipal solid waste: Plastics. 11 Oct. 2007. <http://www. epa.gov/epaoswer/non-hw/muncpl/plastic.htm>.

Evans, M.R. and D.L. Hensley. 2004. Plant growth in plastic, peat, and processed poultry feather fiber growing containers. HortScience 39:10121014.

Frank, C.A., R.G. Nelson, E.H. Simonne, B.K. Behe, and A.H. Simonne. 2001. Consumer preferences for color, price, and vitamin C content of bell peppers. HortScience 36:795800 .

Garthe, J.W. and P.D. Kowal. 1993. Recycling used agricultural plastics. Penn State Fact Sheet C-8. 26 Oct. 2009. <http://www.abe.psu.edu/ extension/factsheets/c/C8.pdf $>$.

Gladwin, T.N., J.J. Kennelly, and T.-S. Krause. 1995. Shifting paradigms for sustainable development: Implications for management the- ory and research. Acad. Manage. Rev. 20:874 907.

Green, P.E. and K. Helsen. 1989. Cross-validation assessment of alternatives to individual-level conjoint analysis: A case study. J. Mktg. Res. $26: 346-350$

Guagnano, G.A., T. Dietz, and P.C. Stern. 1994. Willingness to pay for public goods: A test of the contribution model. Psychol. Sci. 5:411-415.

Hair J.F., Jr, R.E. Anderson, R.L. Tatham, and W.C. Black. 1998. Multivariate analysis. 5th Ed. Prentice Hall, Upper Saddle River, NJ.

Hopman, J.K.K., J.H. van Niejenhuis, and J.A. Renkema. 1996. Application of conjoint analysis to elicit growers' preferences for horticultural location in the Netherlands. Acta Hort. 429:181-188.

Internet World Stats. 2009. Usage and population statistics. 13 Aug. 2009. <http://www.internet worldstats.com/stats.htm>.

Kale, G., T. Kijchavengkul, R. Auras, M. Rubino, S. Selke, and S.P. Singh. 2007. Compostability of bioplastic packaging materials: An overview. Macromol. Biosci. 7:255-277.

Kelley, K.M., B.K. Behe, J.A. Biernbaum, and K.L. Poff. 2002. Combinations of colors and species of containerized edible flowers: Effect on consumer preferences. HortScience 37:218-221.

Kotler, P. and G. Armstrong. 2001. Principles of marketing. 9th Ed. Prentice Hall, Upper Saddle River, NJ.

Kotler, P. and K. Keller. 2006. Marketing management. 12th Ed. Prentice Hall, New York, NY.

Laroche, M., J. Bergeron, and G. Barbaro-Forleo. 2001. Targeting consumers who are willing to pay more for environmentally friendly products. J. Consum. Mark. 18:503-520.

Lin, B., S. Payson, and J. Wertz. 1996. Opinions of professional buyers toward organic produce: A case study of Mid-Atlantic market for fresh tomatoes. Agribusiness 12:89-97.

Lubick, N. 2007. Plastics in from the bread basket. Environ. Sci. Technol. 1:6639-6640.

Martin, S. 2008. Walters gardens goes to Elle plugs. Branch Smith Publishing, Ft. Worth, TX. 26 Oct.
2009. <http://www.gmpromagazine.com/Article. aspx?article_id=13809>.

McCullough, D. 1998. Web-based market research: The dawning of a new age. Direct Marketing 61:36-38.

Murphy, J.J., P.G. Allen, T.H. Stevens, and D. Weatherhead. 2005. A meta-analysis of hypothetical bias in stated preference valuation. Environ. Resour. Econ. 30:313-325.

Ottman, J.A. 1998. Green marketing: Opportunity for innovation. NTC, Lincolnwood, IL

Pearson, D. and A. Bailey. 2009. Sustainable horticultural supply chains: The case of local food networks in the United Kingdom. Acta Hort. 831:131-137.

Philip, C. 2008. Supply chain efficiencies and the growth of category management in the horticultural industry. Report for Nuffield Australia Farming Scholars.

Purser, R.E., C. Par, and A. Montuori. 1995. Limits to anthropocentrism: Toward an ecocentric organization paradigm? Acad. Manage. Rev. 20:1053-1089.

Russo, M.V. and P.A. Fouts. 1997. A resourcebased perspective on corporate environmental performance and profitability. Acad. Manage. J. 40:534-559.

SAS Institute Inc. 1987. SAS user's guide: Statistics. 5th Ed. SAS Institute Inc., Cary, NC.

Schegelmilch, B.B., G.M. Bohlen, and A. And Diamantopoulos. 1996. The link between green purchasing decisions and measures of environmental consciousness. Eur. J. Mark. 30:35-55.

Simonne, A.H., B.K. Behe, and M.M. Marshall. 2006. Consumers prefer low-priced and high lycopene-content fresh-market tomatoes. HortTechnology 16:674-681.

Straugh, R.D. and J.A. Roberts. 1999. Environmental segmentation alternatives: A look at green consumer behavior in the new millennium. J. Consum. Mark. 16:558-573.

Van de Wetering, P. 2008. Packaging sustainability: Straw pots. Greenhouse Product News 18:30-37.

White, J.D. 2009. Container ecology. Growertalks $72: 60-63$ 